\title{
Reframing the narrative on summer school: How student partnership led to meaningful change
}

Leslie Williams, School of Nursing, Eastern Kentucky University, USA.

Carolyn Grace, Department of English, Eastern Kentucky University, USA.

*Russell Carpenter, Department of English, Eastern Kentucky University, USA.

Contact: $\underline{\text { russell.carpenter@eku.edu }}$

At our institution-Eastern Kentucky University (EKU), a regional, teaching-focused university in the United States-summer session (known as EKU Summer) now represents an important academic opportunity for students. As Kopp (2016) has explained, summer session programs are a "problem-solving and innovating force within the university to help deal with . . . issues, such as reducing time to earn a degree, improving retention rates, creating capacity, and supporting enrollment management" (p. 3). In the redesign of EKU Summer, a large-scale initiative involving numerous university stakeholders, the Students-as-Partners (SaP) model, and, in particular, student partners were central to the process. Through reflection based on the lived experience of partnership, we offer ways in which this model was critical to the success of the EKU Summer redesign.

The process involved implementing a number of important changes to EKU Summer, including offering students more online course options, scheduling courses at times that are preferable to students, and prioritizing terms that are ideal for the course and delivery. By using this approach, which was driven by partnership and student involvement, fewer classes overlapped, so there was less competition for students' time, and students were more available to take multiple courses if they chose to do so. Making these large-scale changes, however, meant involving students and student input in each phase throughout the process. We used the partnership model, ensuring a broader scope to include student voices. This change made the process richer and more directly linked to the members involved through ongoing collaborations wherein each partner's perspective on the project added value and factored in the EKU Summer redesign.

In this reflective essay, an undergraduate nursing student, a graduate creative writing student, and a faculty member (the assistant provost of a multi-unit program, summer coordinator, and professor of English) reflect on the process of situating student partners in reenvisioning EKU Summer. In this model, students played a leading role in shaping the academic planning, research, design, and implementation of all areas of EKU Summer. This included significant decisions such as courses scheduled, standard terms and times when the majority of courses would be offered to best suit students, and delivery method (on-ground or online). 
While, importantly, a culture shift has emerged, driven by student-partner input, the process of partnership revealed new, diverse, and innovative ideas for success focused on strategies for students to "stay caught up" or "get ahead" in their degree progression, priorities that were cultivated via partnership reflection.

Much like Cook-Sather et al. (2014) suggested, this partnership was designed with a focus on respect, reciprocity, and responsibility. We agree with Mercer-Mapstone et al. (2017) that "'Students as Partners' (SaP) embraces students and staff (including academic/faculty and professional staff) working together on teaching and learning in higher education" (p. 2). In an effort to showcase the significance and value of the EKU Summer School model and student partnership, we highlight reflection focused on:

- Designing a student-centered model for EKU Summer planning,

- Emphasizing high-quality teaching and learning experiences in the planning process, and

- Engaging students in academic success strategies throughout the process.

As demonstrated through this reflection, when carefully and intentionally designed, student partnerships enhance the outcomes and collaborative practices of all involved and transcend students, faculty, and staff working together.

\section{WAYS PARTNERSHIP WAS IMPLEMENTED}

As Felten et al. (2016) have explained, "Collaboration is a central element in alignment and the key to making traditional, rigid barriers between our organizational structures more permeable and seamless" (p. 111). In an effort to reduce barriers and encourage seamless collaboration and partnership that transcend traditional structures, we designed EKU Summer working groups comprised of students, faculty, and academic staff from a diverse range of areas and disciplines across campus. We invited partners based on their potential for valuable input into redesigning areas of priority (or previous challenges) in EKU Summer. Given the focus on creating a schedule that was responsive to student need, student partners were a central focus throughout the process. We aligned student partners with faculty and staff within organizational and collaborative frameworks. These frameworks were situated in each member's appreciation and understanding of the process and need for open dialogue, willingness to share complex perspectives while making these perspectives visible for each partner to receive ideas openly, and commitment to preparing for planning sessions or meetings in anticipation of making impactful contributions.

We implemented partnership with a focus on ways in which these values-shared across all partners-would not only yield outcomes but also valuable experiences in the process. The focus on respect allowed each partner to ensure that ideas and priorities would be heard and carefully considered, reciprocity allowed for partners to collaborate knowing that each perspective is valuable and that the exchange should be prioritized, and responsibility ensured that each partner had accountability in sharing expertise, learning experience, and outcomes. We found that partnership methods were critical to several priority areas that allowed four meaningful changes to take place: 
- Understanding what delivery method(s) students prefer for EKU Summer courses and why;

- Planning and implementing marketing and communication to best reach students, faculty, advisors, and staff across the university;

- Designing and providing input on EKU Summer initiatives to support diversity; and

- Gathering input on the design of a student-centered schedule that would allow for enhancements to teaching and learning experiences while accelerating pathways to degree completion.

\section{Process of partnership}

The EKU Summer redesign began with a partnership between the summer coordinator and a focus group composed of diverse students to discuss student needs and expectations regarding courses offered, schedule options, areas of need, and barriers. Student-partner perspectives shaped priorities for designing a student-centered summer session, including three areas that emerged as part of the process:

1. Messaging that resonates with students,

2. Student populations in need of summer courses, and

3. Reasons students enroll (or barriers to enrollment) in summer courses.

One of the priorities for student partners was to increase access to courses that students need to complete their degree in the delivery methods (online or on-ground) that they prefer and offered during terms or times that they were most available and interested in taking courses. The student partnership involved open and in-depth dialogues focused on messaging that would communicate the significance of continuing their academic progress during the summer. Student input revealed that the heart of successful academic progress for students during summer meant that the university needed to offer more options for students to access courses and that they could take classes while pursuing other commitments, including professional obligations, employment, or time with family.

We found that the partnership approach allowed four themes to emerge specifically from student partners, a leading voice in the process:

1. Summer is a time for all students to continue their education,

2. Students can pursue their education while involved in other activities,

3. Students need courses during terms and times that best fit their schedules and via deliveries that allow for flexibility, and

4. Students need to know the benefits of taking summer courses (including saving money, accelerated time to degree, and credit recovery).

Reflection allowed for an understanding of the process that emerged and a focus on these transformation priorities, with an emphasis on the design of this partnership model related to active listening across and among all partners, shared leadership and perspective, equal voice in 
providing insights and analysis, and an expectation of preparedness across meetings and workflows.

\section{Designing a student-centered model for EKU summer planning}

EKU Summer course schedules, terms and times, and course delivery decisions were informed by data derived from student surveys, historic scheduling practices, and enrollment trends over five years. We based these processes on big questions that did not have clear or obvious answers. Data collection was valuable in the partnership process, and each partner had an important role in shaping designs and methods. We recognized that our focus on asking big questions, while ambitious, allowed multiple pathways for each partner to contribute, a value that ensured that all perspectives were respected across the stages of the EKU Summer redesign. Meetings focused on analysis; for example, we allowed student, staff, and faculty partners to review data-equally shared-in advance. Ensuring that each partner's perspective was equally important when coming around the table to discuss the results allowed for fluid conversations that informed redesign priorities. We found that focusing on solving problems or achieving goals, rather than setting rigid agendas, allowed each partner to have an equitable voice in discussions and how results could be used to enhance our work. Collaborations that situated partners with diverse perspectives and experiences in regular conversation with one another, aligned to shape possible pathways or outcomes and which allowed for positive working dynamics that adjusted traditional hierarchical structures, were a highlight of the partner model. The dynamic was open and honest, with each partner engaged. Our responsibilities were equally shared, with each partner reviewing information and scenarios in a persistent, iterative process of listening-designing-sharing-acting that allowed for distributed responsibilities.

\section{Emphasizing teaching and learning experiences in the planning process}

We value our university's prioritization of the student experience. Partners value the institutional positioning as a university of opportunity. Through the design of the partnership, each member was positioned to engage in open dialogue and planning of how EKU Summer teaching and learning workflows could be shaped at a large scale. In the problem-solving process, we developed scenarios, flipped the conversation to focus on learner needs, and established models to reveal blind spots. Through gathering or analyzing data, inviting input, or coordinating discussions, the institution's teaching and learning mission allowed for all partners to bring perspectives of value, all of which allowed us to remain motivated, inspired, and focused. We understood, though, that to deliver on our goal of expanding opportunity and access, we needed to value ways in which teaching and learning could be enhanced (or were inhibited) by large-scale decisions such as schedules or delivery method. Together, we realized the many ways that these two sides-planning on the one hand and teaching and learning on the other-are linked, a priority that could not have been viewed outside of a true partnership design. Experiencing in powerful ways that EKU Summer design decisions impacted teaching and learning, which served as motivating factors for all partners, in turn allowed us to either create opportunities or recognize areas where possible needs had been overlooked. Planning processes were envisioned, though, to ensure that we were not simply inspired to achieve an 
outcome or result but that we each learned something from immersing ourselves within the process.

\section{Engaging students in academic success strategies throughout the process}

In open, honest, and engaged dialogue that spanned multiple semesters, conversations expanded to include academic success strategies that, through our planning, emerged as prominent priorities. We coordinated discussions and summarized planning sessions that aligned shared values about data to ask and respond to partners' questions regarding potential impact on academic success factors such as student interest in a course and ability to be successful during a summer session. Such questions emerged as a result of balanced, scaffolded, and intentionally designed collaborations wherein all partners shared in the responsibility of bringing honest perspectives to the discussion and planning. We highlighted student perspectives and experiences while placing them in the larger context of the institution alongside those of faculty and staff partners. In planning, design, and facilitation, we knew that each partner must be equally represented and that each perspective brought a unique and valuable viewpoint about academic success.

\section{REFLECTION ON LIVED PARTNERSHIP EXPERIENCE}

The process implemented was new and required regular meetings, ongoing discussions inside and outside of the meeting room, and sustained input on data and plans. All partners were new to this initiative and, thus, willing to approach it with fresh ideas. Central to the process was our willingness to (a) ask questions that had not been asked and (b) commit to the process fully, which meant reading closely, listening emphatically, and pursuing implementation with commitment and focus.

For student partners, it was the first time they had been invited to provide sustained and ongoing input into such a large-scale institutional initiative. While at first the process seemed vast, the partnership design allowed for an entry point into shaping high-stakes and complex decisions that would impact all members of the campus community. Reviewing dataand contributing perspectives to discussions and shaping plans-created valuable teaching and learning experience. We learned, together, how to ask important questions, how to visualize new trends, and ways in which we could all move forward collaboratively so that each perspective was represented through meaningful experiences and outcomes-the change that resulted from the partnership. Openness in the process allowed for an unwavering, ongoing commitment from all partners. We understood that we not only could learn but would have a better outcome if all could see their concept and values represented in the process.

\section{HOW PARTNERSHIP SHAPED FUTURE STUDENT-PARTNER GOALS}

This partnership reiterated ideas that we already had about collaboration, but the ways we shaped the collaboration allowed for more meaningful and intentional planning processes. Specifically, though, we found that this partnership revealed five important future goals for similar designs and processes, based on the broader, collective learning that took place from the partners involved and skills developed from the partnership experience:

- Establish ambitious goals for all partners, 
- Design processes that are safe for all partners,

- Select partners carefully and intentionally while prioritizing diversity,

- Invite students to help shape the difficult decisions, and

- Commit to mentoring peers and students throughout the process through regular reflection.

With large-scale processes such as the one that led to the redesign of EKU Summer, we recognized that learning takes place along the way, not only in decision-making meetings but also in discussions between formal sessions. In addition, partnership within the context of such a large-scale project can provide teaching opportunities that extend learning beyond the classroom while humanizing long-term and complex decision-making that forms sustainable and impactful changes. We found that partners benefitted most from experiences that made designs and decisions transparent through carefully situated and intentional practice.

\section{APPLICATIONS FOR FUTURE PARTNERSHIP PLANNING}

Reflecting on the process of partnership as an approach to redesigning EKU Summer reveals four applications that can be scaled and implemented in planning future partnerships. We find these valuable as ways to improve our own processes and recommend them as planning strategies for partnerships in the future.

1. Design partnerships with partners in mind. We considered the partners we were inviting to plan with us, their experiences, and the values they would offer alongside the other partners involved.

2. Focus attention and efforts on the process itself, which can yield learning experiences across partner roles. Thinking and acting carefully and intentionally in the design of discussion, meeting, or analysis formats can ensure that all partners are committed and that their perspectives are recognized as integral to the outcome.

3. Involve all partners in decisions and prioritize learning in each phase of the partnership. We see these aspects of partnership as complementing one another.

4. Design and prioritize partnerships that lead to meaningful change. Meaningful change occurs when all partners are able to engage in both teaching and learning. Moreover, partners can apply their experiences in different contexts within the partnership or in future partnerships.

NOTE ON CONTRIBUTORS

Leslie Williams is an undergraduate student in the School of Nursing at Eastern Kentucky University.

Carolyn Grace is a graduate student pursuing the MFA in Creative Writing at Eastern Kentucky University.

Russell Carpenter is Assistant Provost and Professor of English at Eastern Kentucky University. 


\section{REFERENCES}

Cook-Sather, A., Bovill, C., \& Felten, P. (2014). Engaging students as partners in learning and teaching: A guide for faculty. Jossey-Bass.

Felten, P., Gardner, J. N., Schroeder, C. C., Lambert, L. M., \& Barefoot, B. O. (2016). The undergraduate experience: Focusing institutions on what matters most. Jossey-Bass.

Kopp, B. (2016). Summer session: Present state and future directions. Summer Academe: $A$ Journal of Higher Education, 10. http://doi.org/10.5203/sa.v10i0.575

Mercer-Mapstone, L., Dvorakova, S. L., Matthews, K. E., Abbot, S., Cheng, B., Felten, P., Knorr, K., Marquis, E., Shammas, R., \& Swaim, K. (2017). A systematic literature review of students as partners in higher education. International Journal for Students as Partners, 1(1), 1-23. https://doi.org/10.15173/ijsap.v1i1.3119 